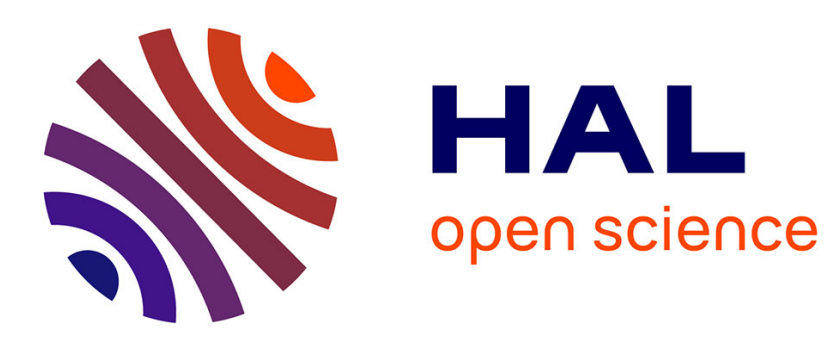

\title{
EPMA and ellipsometric characterization of PECVD boron-carbon films
}

\author{
A. Kanaev, S. Rybakov, M. Churaeva
}

\section{To cite this version:}

A. Kanaev, S. Rybakov, M. Churaeva. EPMA and ellipsometric characterization of PECVD boron-carbon films. Journal de Physique IV Proceedings, 1993, 03 (C3), pp.C3-183-C3-188. 10.1051/jp4:1993323 . jpa-00251380

\section{HAL Id: jpa-00251380 https://hal.science/jpa-00251380}

Submitted on 1 Jan 1993

HAL is a multi-disciplinary open access archive for the deposit and dissemination of scientific research documents, whether they are published or not. The documents may come from teaching and research institutions in France or abroad, or from public or private research centers.
L'archive ouverte pluridisciplinaire HAL, est destinée au dépôt et à la diffusion de documents scientifiques de niveau recherche, publiés ou non, émanant des établissements d'enseignement et de recherche français ou étrangers, des laboratoires publics ou privés. 


\title{
EPMA and ellipsometric characterization of PECVD boron-carbon films
}

\author{
A.I. KANAEV, S. Yu. RYBAKOV and M.N. CHURAEVA \\ Institute of Physical Chemistry, Academy of Sciences, Leninsky pr. 31, 117915 Moscow, Russia
}

\begin{abstract}
The characteristics of $a-B / C: H$ films, produced by PECVD on $\mathrm{si}(100)$ surface using the novel harmless precursorcarborane have been studied. These films proved to be excell ent for protection tokamaks inner surfaces, for they are heat-proof and chemically resistant. EPMA and ellipsometry used together enabled to determine not only the films composition and thickness, but also the density and some other parameters. A special computer program based on YakovitzNewbury method has been developed to study rather thin ( $\sim 100 \mathrm{~nm})$ films by EPMA. Spectroellipsometry was used to determine the wave dependence of the films optical constants. It has been established that $B / C$ ratio grows from 1 to 3.6 with increasing in carborane pressure and does not depend on a substrate temperature and voltage applied. EPMA measurements performed in cooperation with ellipsometry showed the increasing microporosity (up to $40 \%$ ) for the films exposed to the fluence of deuterium ions about $10^{21} \mathrm{~cm}^{-2}$.
\end{abstract}

1. - Introduction.

Boron-containing coatings are generally deposited on inner surfaces of tokamaks with the purpose to improve plasma parameters by preventing D-plasma and metal surface interactions [1]. The knowledge of how CVD regimes influence films characteristics: composition, thickness, porosity, etc. is necessary to perfect the surface protection. Moreover one should be aware of how these characteristics affect the coating resistance to D-ion irradiation and oxygen absorption.

obviously, these films, whether they were produced in a laboratory setup or in a tokamak, should be carefully studied. Electron probe microanalysis (EPMA) proved to be suitable for examination of the filns chemical composition. Although it was designed to study samples more than lim thick, recent computational advances provide quantitative analysis of thin $0.1 \mu \mathrm{m}$ films [2]. EPMA is even more reliable than Auger spectroscopy and ESCA (electron spectroscopy for chemical analysis) for the signal is formed not by a thin outerlayer but by the film as a whole, so it js less sensitive to surface roughness and contamination. What is more BPMA gives mass thickness of a coating without its destruction and makes it possible to analyze actual rough parts of a tokamak.

We used ellipsometry for porous films analysis in order to determine linear thickness, optical constants and porosity of the films (EPMA only gives values of mass thickness [2]). 
So, the main purpose of this paper is to devise a suitable technique for coatings characterization just after PECVD ( in a laboratory setup or in a tokamak) or during their aging in air and under D-ions irradiation.

\section{Experimental procedures.}

PECVD was performed in the laboratory setup ( described in details in [3]) by de glow discharge plasma at $p=3 \times 10^{-3}-5 \times 10^{-2}$ torr, substrates temperature $\mathrm{T}=50-250^{\circ} \mathrm{C}$. The ion energy was $20 \mathrm{eV}$, while the sample was at floating potential, and it was $500 \mathrm{ev}$, if the voltage was applied. 1,7-dicarbo-closo-dodecaborane(12) $\mathrm{C}_{2} \mathrm{~B}_{10} \mathrm{H}_{12}$ - a crystalline powder

with high value of saturated vapor pressure - was used as the precursor for PECVD in the laboratory setup and in $T-3 M$ and $T-11 M$ tokanaks as well [4]. Unlike diborane and trimethyl borane used before, this precursor is accident proof and is not toxic [5].

Experiments on D-ion irradiation have been carried out in the same laboratory setup, $D_{2}^{+}$-ion fluence being $3 \times 10^{16} \mathrm{~cm}^{-2} \mathrm{~s}^{-1}, D_{2}^{0}$-fluence $2 \times 10^{16} \mathrm{~cm}^{-2} \mathrm{~s}^{-1}$. The ions energy was $50 \mathrm{eV}$, substrate temperature was in the range of $100-500^{\circ} \mathrm{C}$.

EPMA measurements have been carried out using microanalyzer CAMEBAX, equipped with lead stearate crystal (ODPb) for light elements analysis. Accelerating voltage was $E_{0}=10 \mathrm{kV}$, beam current $I=100 \mathrm{~mA}$, at the normal beam incidence and $\psi=40^{\circ}$ take off angle. In order to avoid radiation damage the beam was defocused to a $50 \mathrm{~km}$ spot. Boron, diamond and silicon dioxide samples were used as standards for boron, carbon and oxygen elemental analysis respectively. A special plate located just above a sample and cooled by liquid nitrogen was used to prevent surface contamination with hydrocarbons.

EPMA is generally used for analysis of bulk samples comprising heavy elements with $Z>10$. The analysis of thin films ( $d<1 \mu \mathrm{m}$ ) comprising light elements: boron, carbon or oxygen meets difficulties $[6,7]$. Xray lines of these elements can be strongly affected by shifts or shape alternations, so they should be accounted for when measuring characteristic X-ray radiation intensity. As for the shape, G.F.Bastin suggested that a correction area-peak factor (APF) measured in a special experiment was used and K-ratio should be calculated from

$$
K=\left(I_{\text {sam }} / I_{\text {stan }}\right) \text { APF, }
$$

where $I_{\text {sam }}-K_{a}^{-1 i n e ~ i n t e n s i t y ~ o f ~ a ~ s a m p l e ~ a n d ~} I_{\text {stan }}{ }^{-}$of a standard. The line shift can be taken into account by some special spectrometer adjustment during $\mathrm{I}_{\text {sam }}$ and $\mathrm{I}_{\text {stan }}$ measurement.

The experiments performed on boron-carbon containing samples with $B / C$ from 1 to 3.6 showed that the line shift $\Delta \lambda$ and APF depend weakly on film composition and oxygen content. Their values are presented in the Table 1 .

Table 1. Correction factors for EPMA analysis of a-B/C films.

\begin{tabular}{|l|l|c|c|}
\hline element & standard & $\Delta \lambda=\lambda_{\text {sam }}-\lambda_{\text {stan }}, \mathrm{nm}$ & APF \\
\hline B & boron & 0.0121 & $1.06 \mp 0.01$ \\
d & diamond & 0.0222 & $0.93 \mp 0.01$ \\
0 & Sio $_{2}$ & 0.0081 & 1.0370 .01 \\
\hline
\end{tabular}


Chemical composition (except for hydrogen) and mass thickness of a-B/C films were calculated using a special computer program, based on Yakovitz-Newbury method. There are two versions of the program: in FLEXTRAN for PDP $11 / 05$ (our experimental setup is under its control) and in Microsoft BASIC 4.5 for PC $286 \mathrm{AT} / \mathrm{XT}$. This universal program can be applied to the films comprising elements from $B$ to $U$; K-ratio, Eo and $\psi$ values being the starting for the calculation.

The algorithm takes properly into account $x$-ray absorption inside a film ( mass absorption coefficients taken from $[6,7]$ ), that is of special importance for light elements analysis. The films were considered uniform along the depth. Secondary fluorescence was not taken into account for it is negligibly small in B-C-B systems. It should be noted that although there is up to $30 \%$ at of hydrogen in the film, it does not affect $B-K a$ and $C-K a$ radiation intensities [2] and it may be neglected.

The accuracy of the analysis is combined of the statistical uncertainty in K-ratio measurement $(3-5 \%)$ and of the calculations accuracy $\sim 7 \%$. The accuracy of mass thickness and composition determination was better than $10 \%$, the accuracy of $B / C$ ratio determination was better than 15\%. These results are supported by the analysis of the standard films, for which mass thickness was measured using weighting.

Fig.l shows the relationship between $\mathrm{C}-\mathrm{Ka} \mathrm{K}$-ratio and carbon mass per area for a-B/C films deposited on silicon. The calculations were performed for $\mathrm{E} \circ=10 \mathrm{kV}$ and $\psi=40^{\circ}$. The intensity is mainly proportional to carbon content in the coating, but the slope of the curve depends on boron content. Variations in the proportionality factor are related to strong carbon Ka-line absorption in boron. In contrast, $\mathrm{B}-\mathrm{Ka}-1$ ine absorption in carbon is not significant, so the curves slopes weakly depend on carbon content in the coating (Fig. 2). These calibration curves were used for a brief evaluation of the results obtained.

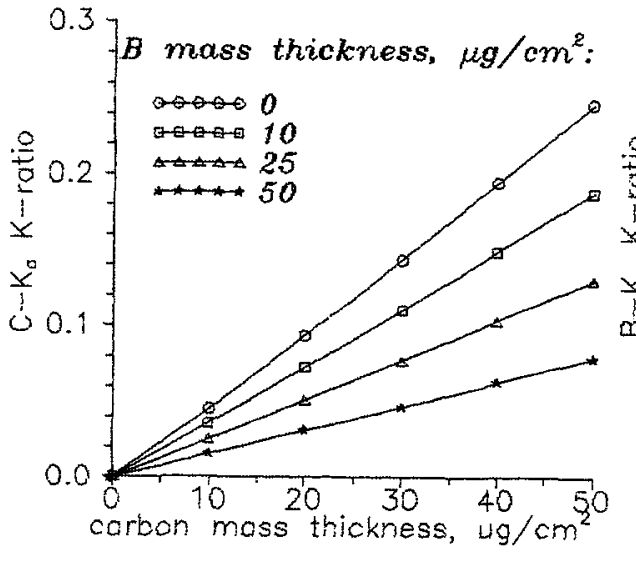

Fig. 1. Carbon Ka-1ine Kratio dependence on carbon mass thickness for a-B/C film deposited on Si (diamond as a standard).

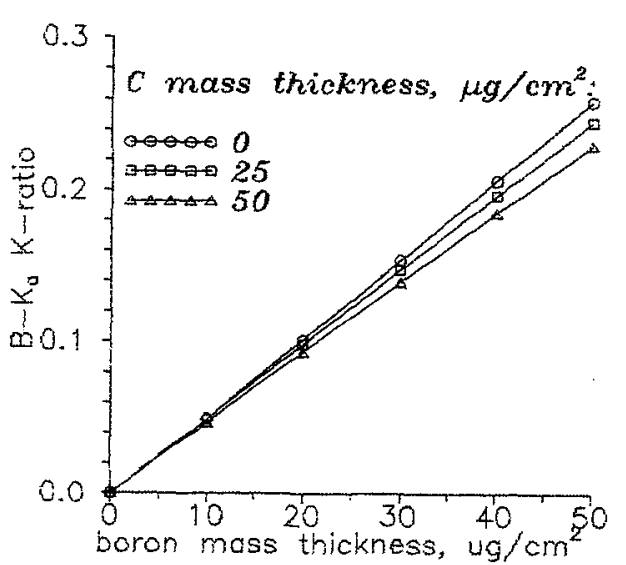

Fig.2. Boron Ka-line K-ratio dependence on boron mass thickof boron in $a-B / C$ film depositon $\mathrm{Si}$ (pure boron as a standard). 
Ellipsometric measurements were performed using Gaertner Lll9xuV manual ellipsometer, equipped with Bausch \& Lomb grating monochromator, in the range of wavelength $\lambda=360-660 \mathrm{~nm}$. The experimental setup and the calculating procedure are described in [8].

\section{3. - Results and discussion.}

The chemical composition of a-B/C films ( B, C and 0 content) determined by EPMA is shown in Fig.3. It was practically the same for different substrates and did not change when the voltage had been applied to the substrate, the diversity of mass thicknesses was less than $15 \%$. But if the deposition pressure increased from $3 \times 10^{-3}$ to $5 \times 10^{-2}$ torr, $B / C$ ratio rose from 1.6 to 3.6 approaching the value $B / C=5$ characteristic of the precursor.

It should be mentioned that oxygen content in just deposited films was less than $3 \%$ at. This amount grew to $20 \%$ at after the films had been aged in air for a year. Further observation showed no changes, and that points to the saturation of the process.

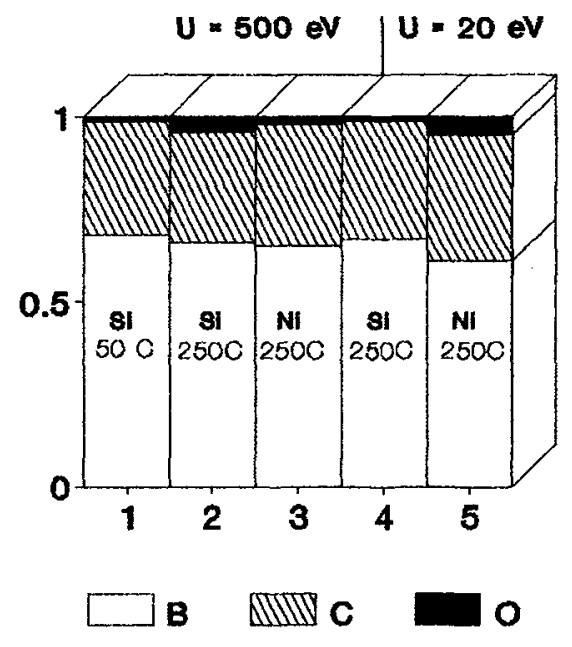

a)

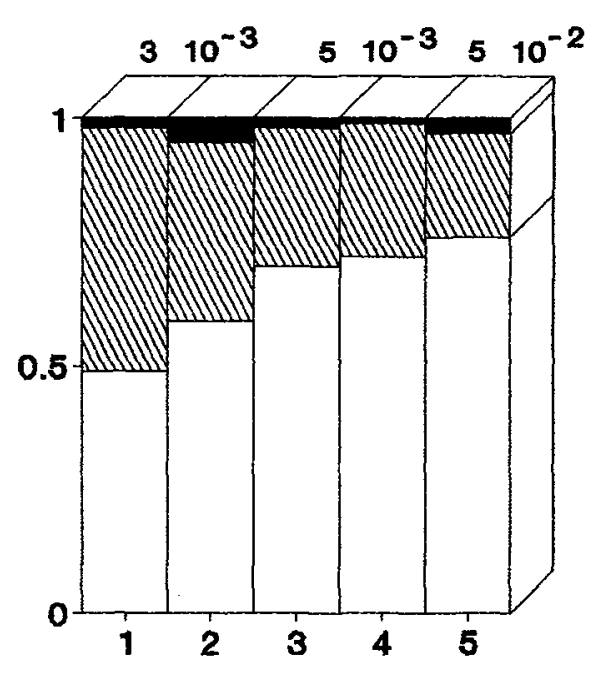

b)

Fig.3. a-B/C films composition by EPMA, on $N i$ and $S i$ substrates, at floating potential (20ev) and at $500 \mathrm{~V}$ bias (a), at different deposition pressures (b).

It is important that the $a-B / C$ deposits should be resistant to Dplasma exposure. EPMA analysis of the films exposed to D-ion irradiation showed that $B / C$ ratio did not change up to $3.510^{21} \mathrm{~cm}^{-2}$ dose in the films with $B / C>2.5$, but decreased in the films with lower $\mathrm{g} / \mathrm{C} \mathrm{ra}-$ tio. Mass thickness went down with the dose, the rate of erosion being practically constant. Thickness values obtained using ellipsometry disagreed with those of EPMA determined in approximation of constant density (Fig. 4 ).

To clarify these facts we used ellipsometry with immersion, in other words we measured azimuth of polarization spectra of the samples twi- 
ce: just after D-ion irradiation and then after their immersion to hexan ( $n=1.37)$. The experiment showed that not the film thickness, but the refractive index changed with the dose. It means that the film porosity develops under D-irradiation approaching the value $40 \%$ at the highest dose. Judging from the experiments the pores were less than 50nm in size. Ellipsometric data also showed that the pores size decreased in the inner part of the film.

So, the erosion study showed that a-B/C films were highly resistant to D-ion irradiation, for the rate of erosion did not increase with the dose and was 50 times less than that of graphite.
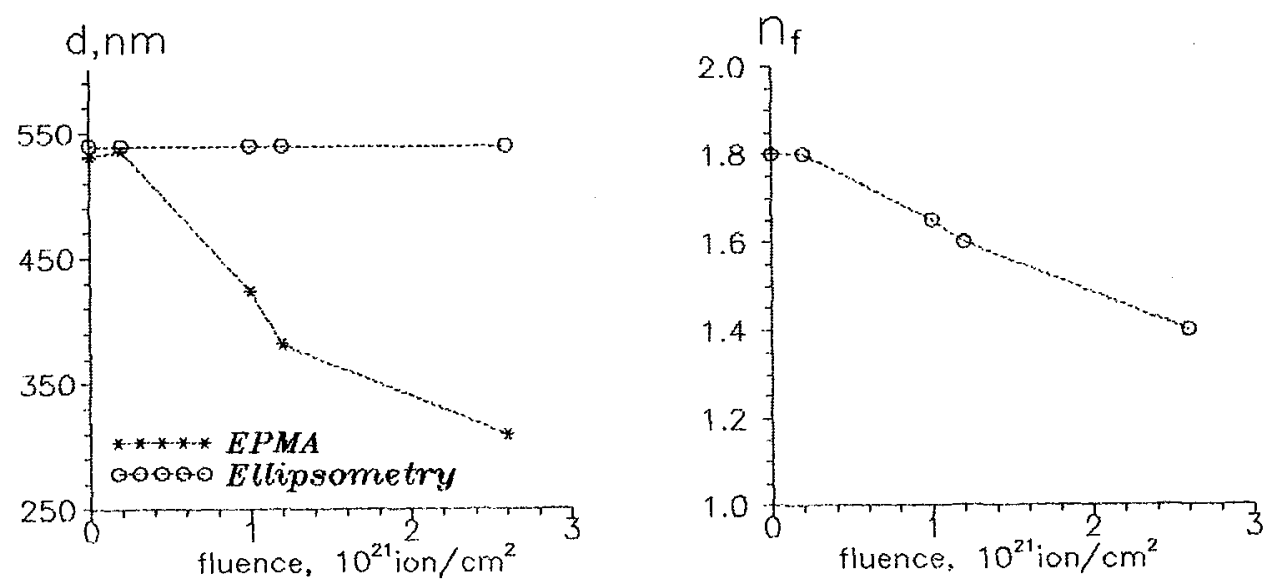

Fig.4. The dose-dependence of the film thickness by EPMA and by ellipsometry, $B / C=2.5$ (a). The dose-dependence of the film refractive index by ellipsometry (b).

4. - Conclusion.

EPMA measurements combined with ellipsometry show considerable promise as the means for PECVD films analysis. It has been established that $B / C$ ratio in a-B/C films grows from 1.0 to 3.6 with increasing in carborane pressure during deposition and does not depend on substrate temperature and voltage applied.

The films absorb oxygen slowly, o-content approachs the saturation value 20\%at within a year. The films exposed to the D-ions fluence about $10^{21} \mathrm{~cm}^{-2}$ exhibit up to $40 \%$ microporosity.

\section{References.}

[1.] Buzhinsky O.I. et al., J.Nucl.Mat. 191-194 (1992) 1413 .

[2] Karduck P., Ammann N., Esser H.G. and Winter J., Fresenius J.Anal.Chem. 341 (1991) 315 .

[3] Sharapov V.M., Kanaev A.T., Zakharov A.P. and Gorodetsky A.E., J.Nucl. Mat. 191-194 (1992) 508.

[4] Buzhinsky 0.I. et al., Abstracts 5th Int.Conf. on Fusion Reactor Materials, Clearwater, Florida, USA (1991) 203.

[5] Westerum E.F.J., Heriques S.J., Mol.Cryst. and Liquid Cryst. 32, 
$1-4$ (1976) 31 .

[6] Bastin G.F. and Heijligers H.J.M., Quantitative EPMA of boron in Binary Borides. Univ. of Technology Eindhoven (1986).

[7] Bastin G.F. and Heijligers H.J.M., Quantitative EPMA of carbon in Binary Carbides. Univ. of Technology Eindhoven (1990).

[8] Churaeva M.N. to be published. 